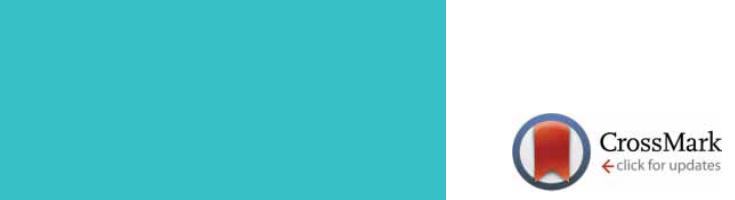

\title{
Comparison of ciliary beat frequencies at different temperatures in young adults
}

\author{
Wilfried Nikolaizik, Jana Hahn, Monika Bauck and Stefanie Weber
}

Affiliation: Dept of Pediatric Chest Medicine, Children's Hospital, Philipps-University Marburg, Marburg, Germany.

Correspondence: Wilfried Nikolaizik, Dept of Pediatric Chest Medicine, Children's Hospital, PhilippsUniversity, Baldingerstrasse, 35043 Marburg, Germany. E-mail: nikolaizamed.uni-marburg.de

\section{ABSTRACT}

Rationale: Direct visualisation of ciliary beat pattern (CBP) and ciliary beat frequency (CBF) has been recommended as the first-line diagnostic test in patients suspected of having primary ciliary dyskinesia (PCD). However, the test procedure is not yet completely standardised, and centres measure the CBF at different temperatures.

Objectives: It was the aim of the study to compare CBF at different temperatures, to establish normative values, to check for age dependency and to measure the temperature on the nasal mucosa of the participants.

Methods: High-speed video-microscopy analysis with a Sisson-Ammons Video Analysis (SAVA) system was used to determine $\mathrm{CBP}$ and $\mathrm{CBF}$ in the participants.

Measurements: Nasal brushings were taken and $\mathrm{CBF}$ was measured in randomised order at three temperatures: $25^{\circ} \mathrm{C}, 32^{\circ} \mathrm{C}$ and $37^{\circ} \mathrm{C}$.

Main results: In total, 100 healthy young adults (74 female, 26 male), aged 20.2-31.9 years, were included in the study. We found a highly significant difference among the groups: the median $\mathrm{CBF}$ was $7.0 \mathrm{~Hz}$ at $25^{\circ} \mathrm{C}, 7.6 \mathrm{~Hz}$ at $32^{\circ} \mathrm{C}$ and $8.0 \mathrm{~Hz}$ at $37^{\circ} \mathrm{C}$. The maximum time period ex vivo was $65 \mathrm{~min}$ and did not differ significantly. However, $\mathrm{CBF}$ was significantly higher when the cilia were kept at a higher temperature before the measurements were made. We found no correlation between CBF and the age of the participants. The median nasal mucosal temperature in our study participants was $30.2^{\circ} \mathrm{C}$ (range $24.7-35.8^{\circ} \mathrm{C}$ ) comparable to the $30.2-34.4^{\circ} \mathrm{C}$ described in the literature.

Conclusions: The most appropriate temperature at which to measure $\mathrm{CBF}$ is $32^{\circ} \mathrm{C}$. In our study, with $95 \%$ confidence for this temperature the CBF was between 6.3 and $9.0 \mathrm{~Hz}$.

@ERSpublications

Equivalent to the nasal mucosa, the most appropriate temperature to measure ciliary beat frequency is $32^{\circ} \mathrm{C}$ https://bit.ly/2GCr2fP

Cite this article as: Nikolaizik W, Hahn J, Bauck MComparison of ciliary beat frequencies at different temperatures in young adults. ERJ Open Res 2020; 6: 00477-2020 [https://doi.org/10.1183/ 23120541.00477-2020]. 


\section{Introduction}

Primary ciliary dyskinesia (PCD) is a heterogeneous group of morphological and functional abnormalities in cilia that can lead to neonatal respiratory distress, recurrent upper or lower respiratory tract disease and male infertility [1]. In almost $50 \%$ of cases dextrocardia is present, and this together with chronic sinusitis and bronchiectasis was originally described as Kartagener's syndrome [2]. PCD is usually considered to be an autosomal recessive genetic disorder. Homozygous or compound heterozygous mutations in $>44$ genes are known to be causative for PCD [3] and correlate with the ciliary beat pattern (CBP) variations [4]. It has been shown that the ultrastructural phenotype has an influence on lung function and body mass index of the patients [5]. The reported prevalence varies widely from 1:2000 to 1:40000 [6]. It is generally accepted that PCD is underdiagnosed and that the diagnosis is made too late [7]. In a longitudinal study over 7 years adult patients with late diagnosis showed impaired forced expiratory volume in $1 \mathrm{~s}\left(\mathrm{FEV}_{1}\right)$ and increased Pseudomonas aeruginosa colonisation [8-10]. There is no single gold standard test available to diagnose PCD $[11,12]$. Appropriate tests include nasal NO measurement, high-speed video-microscopy analysis (HVMA), transmission electron microscopy or immunofluorescence microscopy. Nowadays genotyping of the most common mutations can additionally be used as a diagnostic tool [4, 13]. Direct visualisation of $\mathrm{CBP}$ and ciliary beat frequency (CBF) by HVMA has been recommended as the first-line diagnostic test in patients suspected of having PCD [12]. The accuracy of HVMA has recently been proven [14]. However, ciliary function varies under differing conditions such as temperature and $\mathrm{pH}$ [12]. The physiological nasal mucosal temperature has been shown to range from $30.2^{\circ} \mathrm{C}$ to $34.4^{\circ} \mathrm{C}$ [15]. Some centres measure $\mathrm{CBF}$ at $37^{\circ} \mathrm{C}[16-19]$ and others at lower temperatures, usually at $25^{\circ} \mathrm{C}[4,20-22]$. Therefore, centres need to define their own normative data until a consensus is reached to allow standardisation of methods and reporting between centres [12]. So far, no study has compared CBF at different temperatures. A correlation between $\mathrm{CBF}$ and age of the individuals has been discussed controversially. It was the aim of the study to compare $\mathrm{CBF}$ at the three temperatures $25^{\circ} \mathrm{C}, 32^{\circ} \mathrm{C}$ and $37^{\circ} \mathrm{C}$ to establish normative values for these temperatures and check for age dependency. Due to restrictions of the ethics committee, the study could only be performed in adults and not in healthy children. In the same individuals we also intended to measure the temperature on the nasal mucosa noninvasely to determine the optimal temperature for analysis of CBF.

\section{Study subjects}

For ethical reasons it was not possible to include healthy children in the study. We asked healthy adult students without lung disease, allergy or acute infection to take part. All students who showed interest filled in a questionnaire and were interviewed on their medical history. Exclusion criteria were asthma or asthma symptoms, hay fever, eczema, exercise limitation, smoking or any medication that might have an influence on lung function or mucociliary clearance. Students who met no exclusion criteria were considered "lung healthy". In dubious cases lung function testing was offered. The healthy volunteers eligible for the study were informed verbally and in writing about the trial. Informed consent was obtained from all participants. The participants were free to withdraw from the study at any time. Approval from the ethics committee was obtained before the start of the study. The declaration of Helsinki was always followed.

Samples were only taken in individuals who were not receiving nasal steroids or decongestants, and who did not show signs of acute respiratory infection for at least 3 weeks in order to minimise secondary ciliary dyskinesia.

\section{Study design}

$\mathrm{CBP}$ was assessed and $\mathrm{CBF}$ was measured in every participant at three temperatures in randomised order: in participants with an uneven birth date in ascending order first at $25^{\circ} \mathrm{C}$, then at $32^{\circ} \mathrm{C}$ and finally at $37^{\circ} \mathrm{C}$; in participants with an even birth date in descending order first at $37^{\circ} \mathrm{C}$, then at $32^{\circ} \mathrm{C}$ and finally at $25^{\circ} \mathrm{C}$. The time interval from nasal brushing to measuring CBF was recorded for the different temperatures.

\section{Methods}

\section{CBP and frequency}

Ciliated respiratory epithelial cells were obtained from the participants by nasal brushing as previously described [3]. The material was suspended in RPMI 1640 medium and stored in a water bath preheated to the required temperatures. Microscopy was carried out using a Nikon microscope solution system with an inverted phase-contrast microscope ECLIPSE Ts2R-FL, CFI Super Plan Fluor ELWD ADM 40x C/0.60/3.6 objective and TPX-TS2R temperature control plate (NIKON GMBH Microscope Solutions, Düsseldorf, Germany).

$\mathrm{CBP}$ and $\mathrm{CBF}$ were evaluated according to the published recommendations [4, 23] using a Sisson-Ammons Video Analysis (SAVA) system [24]. Videos of beating cilia were recorded using a Basler 
acA1300-200 $\mu \mathrm{m}$ USB3 video camera with $640 \times 480$-pixel resolution and a frame rate of 120 frames per second (Basler AG, Ahrensburg, Germany). CBP was evaluated in real time and in slow motion and considered normal if cilia showed regular forward and recovery strokes and were not disrupted, static, almost static with minimal movements, stiff or beating with reduced amplitude or abnormal circular pattern [4]. Videos with ciliated cell bundles were accepted for analysis while videos of disrupted cells or single ciliated cells were considered to be of insufficient quality and excluded from the analysis [23].

$\mathrm{CBF}$ was measured at five different ciliated cell bundles and two different regions of interest for every ciliated cell bundle. To ensure reliable results the measurements were only accepted if the difference between the two regions of interest did not exceed $10 \%$ and if the difference among the different ciliated cell bundles did not exceed $20 \%$. The mean of the two regions of interest was taken first before the mean from both measurements for every video was calculated as CBF. Whole field analysis was not performed to exclude the influence of outlying measurements. In this way five videos respectively ten measurements were taken into analysis of each individual.

\section{Nasal mucosal temperature}

Participants were enrolled in the study throughout the year. They had time to acclimatise to the room temperature of 20 to $23^{\circ} \mathrm{C}$ for $\sim 30 \mathrm{~min}$ while filling in the questionnaire. The nasal mucosal temperature was measured before nasal brushing using a contactless infrared thermometer Gerathermnon Contact GT-101 (Geratherm Medical AG, Geschwenda, Germany). The object temperature measurement mode was selected, and the temperature of the nasal mucosa was measured twice on both sides from a distance of $4-5 \mathrm{~cm}$. The mean temperature from each side and the mean temperature of both sides were calculated.

\section{Analysis}

Data were analysed with GraphPad Prism version 6.0.7 for Windows (GraphPad Software, San Diego, CA, USA; www.graphpad.com). To test for deviations from the "normal" Gaussian distribution the Kolmogorov-Smirnov test was used. In not normally distributed data the nonparametric Wilcoxon test was used to compare matched pairs. The Mann-Whitney test was used to compare unpaired data. Correlation coefficients were determined using the nonparametric Spearman regression analysis. Percentiles were calculated according to the method described by HyNDMAN and YANAN FAN [25]. Differences associated with probabilities $\mathrm{p}<0.05$ were considered significant.

\section{Results}

\section{Participant characteristics}

In total, 100 healthy young adults (74 females and 26 males) were included in the study. The age was not normally distributed (Kolmogorov-Smirnov normality test: $\mathrm{p}=0.005$ ). The median age was 23.5 years (range 20.2-31.9), and the mean age was 23.9 years (sD 2.7 years).

\section{Participant subgroups}

The participants were randomised depending on their birth date to measure CBF at the three temperatures in ascending order or in descending disorder. In 48 participants with uneven birth dates (35 females and 13 males) $\mathrm{CBF}$ was measured in ascending temperature order from $25^{\circ} \mathrm{C}, 32^{\circ} \mathrm{C}$ to $37^{\circ} \mathrm{C}$. In 52 participants with even birth dates (39 females and 13 males) $\mathrm{CBF}$ was measured in descending temperature order from $37^{\circ} \mathrm{C}, 32^{\circ} \mathrm{C}$ to $25^{\circ} \mathrm{C}$.

The age was not normally distributed in the two groups (Kolmogorov-Smirnov normality test: $\mathrm{p}=0.001$ in the group with uneven birth dates, $\mathrm{p}=0.039$ in the subgroup with even birth date). The age did not differ significantly between the two groups. The median age was 23.4 years (range 20.3-31.0), the mean age was 23.7 years (SD 2.5) in the subgroup with uneven birth dates compared with the median of 23.6 years (range 20.2-31.9), mean 24.1 years (SD 2.8), in the subgroup with even birth dates (Mann-Whitney test $\mathrm{p}=0.454$ ).

\section{Ciliary beat pattern}

CBP showed regular forward and recovery strokes in all participants. No obvious change in beat pattern was observed at the different temperatures.

\section{CBF at different temperatures}

CBF measured at the different temperatures was not normally distributed (Kolmogorov-Smirnov normality test for $\left.25^{\circ} \mathrm{C}: \mathrm{p}<0.001 ; 32^{\circ} \mathrm{C}: \mathrm{p}=0.036 ; 37^{\circ} \mathrm{C}: \mathrm{p}<0.01\right)$. The median $\mathrm{CBF}$ at $25^{\circ} \mathrm{C}$ was $7.0 \mathrm{~Hz}$ (range 6.2-9.6), mean $7.2 \mathrm{~Hz}$ (sD 0.6). The median $\mathrm{CBF}$ at $32^{\circ} \mathrm{C}$ was $7.6 \mathrm{~Hz}$ (range 5.8-9.1), mean $7.6 \mathrm{~Hz}$ (sD 0.6). The median $\mathrm{CBF}$ at $37^{\circ} \mathrm{C}$ was $8.0 \mathrm{~Hz}$ (range 6.5-9.8), mean $8.1 \mathrm{~Hz}$ (SD 0.7). There was a highly significant difference among the three groups (figure 1). 
FIGURE 1 Median and individual results for ciliary beat frequency (CBF) shown at the three temperatures. CBF was significantly higher when measured at higher temperatures (Wilcoxon matched pairs test for $25^{\circ} \mathrm{C}$ versus $32^{\circ} \mathrm{C}$ : $p<0.0001 ; 25^{\circ} \mathrm{C}$ versus $37^{\circ} \mathrm{C}$ : $p<0.0001$; $32^{\circ} \mathrm{C}$ versus $37^{\circ} \mathrm{C}: \mathrm{p}<0.0001$ ).

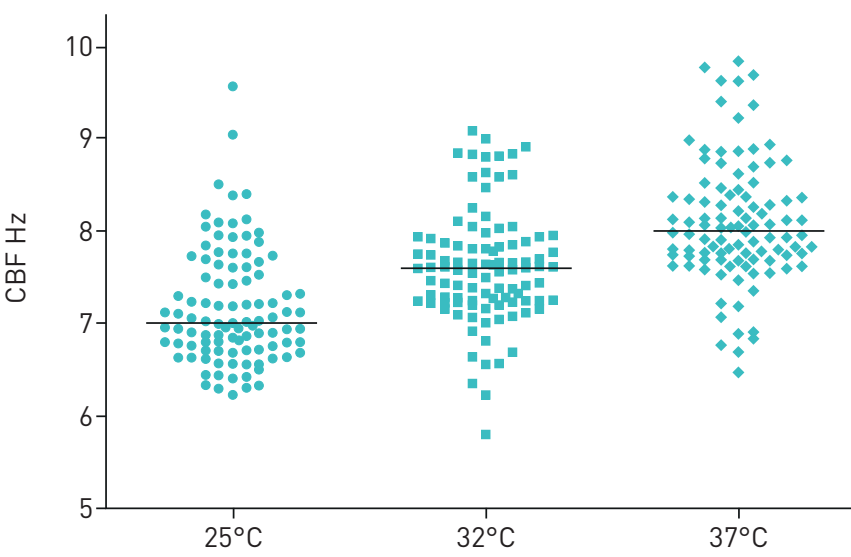

\section{Normal range of $\mathrm{CBF}$}

Since CBF was not normally distributed, the "normal range" defined as $95 \%$ confidence interval was calculated as the interval between the 2.5th percentile and the 97.5th percentile according to HyNDMAN and YANAN FAN [25]. The results are shown in table 1.

CBF in the subgroups

CBF measured at the three temperatures $25^{\circ} \mathrm{C}, 32^{\circ} \mathrm{C}$ and $37^{\circ} \mathrm{C}$ in ascending order $(\uparrow)$ were not normally distributed (Kolmogorov-Smirnov normality test $25^{\circ} \mathrm{C}: \mathrm{p}=0.001,32^{\circ} \mathrm{C}: \mathrm{p}=0.049,37^{\circ} \mathrm{C}: \mathrm{p}=0.031$ ), while the subgroups in descending order $(\downarrow)$ passed the normality test (Kolmogorov-Smirnov normality test $25^{\circ} \mathrm{C}$ : $\mathrm{p}=0.084,32^{\circ} \mathrm{C}: \mathrm{p}=0.10,37^{\circ} \mathrm{C}: \mathrm{p}>0.10$ ). The median $\mathrm{CBF}$ at $25^{\circ} \mathrm{C} \uparrow$ was $6.9 \mathrm{~Hz}$ (range $6.2-9.6$ ), mean $7.0 \mathrm{~Hz}$ (SD 0.6) versus median $\mathrm{CBF}$ at $25^{\circ} \mathrm{C} \downarrow$ of $7.2 \mathrm{~Hz}$ (range 6.4-9.1), mean $7.4 \mathrm{~Hz}$ (SD 0.6). The median $\mathrm{CBF}$ at $32^{\circ} \mathrm{C} \uparrow$ was $7.5 \mathrm{~Hz}$ (range $5.8-8.9$ ), mean $7.5 \mathrm{~Hz}$ (SD 0.5) versus median $\mathrm{CBF}$ at $32^{\circ} \mathrm{C} \downarrow$ of $7.7 \mathrm{~Hz}$ (range 6.2-9.1), mean $7.8 \mathrm{~Hz}$ (sD 0.7). The median $\mathrm{CBF}$ at $37^{\circ} \mathrm{C} \uparrow$ was $7.8 \mathrm{~Hz}$ (range 6.5-8.9), mean $7.8 \mathrm{~Hz}$ (SD 0.5 ) versus median $\mathrm{CBF}$ at $37^{\circ} \mathrm{C} \downarrow$ of $8.3 \mathrm{~Hz}$ (range 6.9-9.8), mean $8.4 \mathrm{~Hz}$ (SD 0.7). The differences between the corresponding subgroups were significant (figure 2 ).

\section{Time periods ex vivo}

Due to the study design the time intervals from nasal brushing to the start of measuring CBF at the three different temperatures, i.e. the time periods ex vivo, were not normally distributed (Kolmogorov-Smirnov normality test for $\left.25^{\circ} \mathrm{C}: \mathrm{p}<0.0001,32^{\circ} \mathrm{C}: \mathrm{p}<0.001,37^{\circ} \mathrm{C}: \mathrm{p}<0.0001\right)$. The median time period ex vivo at $25^{\circ}$ $\mathrm{C}$ was $38.5 \mathrm{~min}$ (range 1.0-63.0), mean $25.5 \mathrm{~min}$ (SD 22.6). The median time period ex vivo at $32^{\circ} \mathrm{C}$ was $24.0 \mathrm{~min}$ (range 15.0-38.0), mean $24.5 \mathrm{~min}$ ( $\mathrm{SD} 4.2 \mathrm{~min}$ ). The median time period ex vivo at $37^{\circ} \mathrm{C}$ was $4.0 \mathrm{~min}$ (range 1.0-65.0), mean $23.6 \mathrm{~min}$ ( $\mathrm{SD} 22.8$ ). The time periods ex vivo did not differ significantly among the three temperatures (Wilcoxon matched pairs test $25^{\circ} \mathrm{C}$ versus $32^{\circ} \mathrm{C}: \mathrm{p}=0.916 ; 25^{\circ} \mathrm{C}$ versus $37^{\circ} \mathrm{C}$ : $\mathrm{p}=0.763,32^{\circ} \mathrm{C}$ versus $\left.37^{\circ} \mathrm{C}: \mathrm{p}=0.500\right)$.

Time periods ex vivo in the subgroups

The time periods ex vivo to measure $\mathrm{CBF}$ at the three temperatures $25^{\circ} \mathrm{C}, 32^{\circ} \mathrm{C}$ and $37^{\circ} \mathrm{C}$ in ascending order $(\uparrow)$ or descending order $(\downarrow)$ were not normally distributed except for $37^{\circ} \mathrm{C} \uparrow$ (Kolmogorov-Smirnov normality test $25^{\circ} \mathrm{C} \uparrow: \mathrm{p}<0.0001,25^{\circ} \mathrm{C} \downarrow: \mathrm{p}=0.049,32^{\circ} \mathrm{C} \uparrow: \mathrm{p}=0.032,32^{\circ} \mathrm{C} \downarrow: \mathrm{p}=0.023,37^{\circ} \mathrm{C} \uparrow: \mathrm{p}>0.10,37^{\circ} \mathrm{C} \uparrow:$ $\mathrm{p}<0.0001)$.

For measuring $\mathrm{CBF}$ at $25^{\circ} \mathrm{C} \uparrow$ the median time ex vivo was 2.0 min (range 1.0-11.0), mean 2.6 min (SD 2.2), for $25^{\circ} \mathrm{C} \downarrow$ the median time was $46.6 \mathrm{~min}$ (range 35.0-63.0), mean 46.6 min (SD 6.1). For measuring $\mathrm{CBF}$ at $32^{\circ} \mathrm{C} \uparrow$ the median time ex vivo was $26.0 \mathrm{~min}$ (range 15.0-38.0), mean $26.3 \mathrm{~min}$ (1 SD 24.3), for

\section{TABLE 1 Normal range of ciliary beat frequencies at the different temperatures}

Temperature ${ }^{\circ} \mathrm{C}$ 2.5th percentile

97.5th percentile

$\begin{array}{llr}25 & 6.3 & 8.8 \\ 32 & 6.3 & 9.0 \\ 37 & 6.7 & 9.8\end{array}$


FIGURE 2 Ciliary beat frequency (CBF) measured at different temperatures in ascending $(\uparrow)$ or descending order ( $\downarrow)$. Data are shown as median and individual results. CBF was always significantly higher in corresponding subgroup in which the measurement was made in descending order $\left(25^{\circ} \mathrm{C}: \mathrm{p}=0.002\right.$; $32^{\circ} \mathrm{C}: \mathrm{p}<0.050 ; 37^{\circ} \mathrm{C}: \mathrm{p}=0.0001$ ).

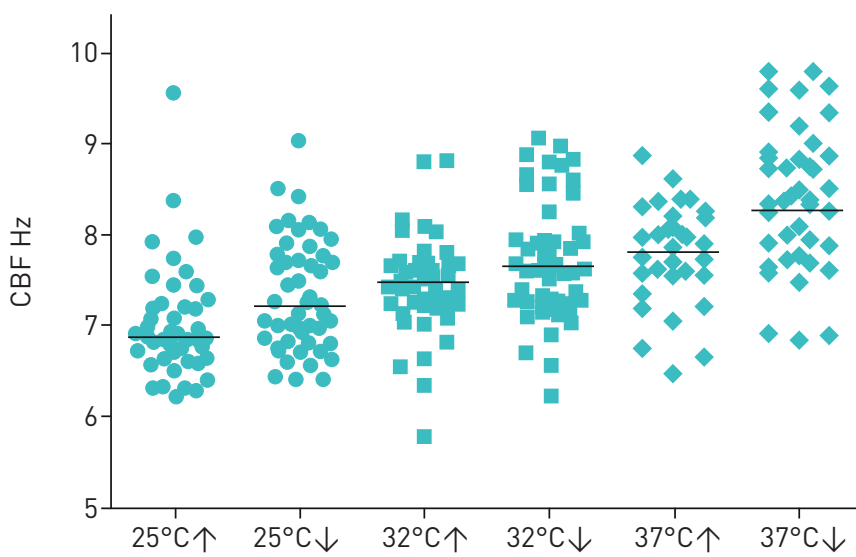

$32^{\circ} \mathrm{C} \downarrow$ the median time ex vivo was 22.0 min (range 17.0-33.0), mean 22.9 min (SD 3.4). For measuring $\mathrm{CBF}$ at $37^{\circ} \mathrm{C} \uparrow$ the median time ex vivo was $47.5 \mathrm{~min}$ (range $34.0-65.0$ ), mean $46.8 \mathrm{~min}$ (SD 6.3), for $37^{\circ} \mathrm{C} \downarrow$ the median time was $2.0 \mathrm{~min}$ (range 1.0-5.0), mean $2.2 \mathrm{~min}$ (SD 1.3).

Due to the randomisation design, the subgroup analysis for $25^{\circ} \mathrm{C}$ respectively $37^{\circ} \mathrm{C}$ revealed significantly shorter time intervals ex vivo when the measurement for the corresponding temperature started immediately after nasal brushing and was not performed at the end (figure 3 ). The time period ex vivo to measure $\mathrm{CBF}$ at $32^{\circ} \mathrm{C}$ was significantly shorter in the subgroup with descending order (figure 3 ). The time periods ex vivo were not significantly different between the subgroups for $25^{\circ} \mathrm{C}$ and $37^{\circ} \mathrm{C}$ when the measurements started with the respective temperature first $(\mathrm{p}=0.584)$ or last $(\mathrm{p}=0.715)$.

Association between CBF and time period ex vivo

Due to the study design, the time intervals from nasal brushing to measurement of $\mathrm{CBF}$ at the different temperatures $25^{\circ} \mathrm{C}, 32^{\circ} \mathrm{C}$ and $37^{\circ} \mathrm{C}$ varied. The association between the time periods ex vivo and $\mathrm{CBF}$ measured at the three temperatures $25^{\circ} \mathrm{C}, 32^{\circ} \mathrm{C}$ and $37^{\circ} \mathrm{C}$ is shown in figure 4 .

\section{Association between CBF and age}

The association between the age of the participants and $\mathrm{CBF}$ measured at the different temperatures $25^{\circ} \mathrm{C}$, $32^{\circ} \mathrm{C}$ and $37^{\circ} \mathrm{C}$ was calculated. There was no correlation for any of the temperatures. Detailed results are shown in figure 5 .

\section{Nasal mucosal temperature}

The nasal mucosal temperatures measured at the right and the left side were not normally distributed on both sides (Kolmogorov-Smirnov normality test right mucosa $\mathrm{p}=0.001$, left mucosa $\mathrm{p}=0.015$ ). The median temperature on the right nasal mucosa was $30.6^{\circ} \mathrm{C}$ (range $24.9-35.8$ ), mean $30.0^{\circ} \mathrm{C}$ (SD 2.3) and the median temperature on the left side was $30.1^{\circ} \mathrm{C}$ (range $24.5-35.8$ ), mean $29.8^{\circ} \mathrm{C}$ (SD 2.3). The difference between the right and the left side was significant (figure 6). Assessing both sides, the median temperature on the nasal mucosa was $30.2^{\circ} \mathrm{C}$ (range $\left.24.7-35.8\right)$, mean $29.9^{\circ} \mathrm{C}\left(\mathrm{sD} 2.3^{\circ} \mathrm{C}\right.$ ).

FIGURE 3 Time periods ex vivo to measure the ciliary beat frequency at the different temperatures in ascending $(\uparrow)$ or descending order

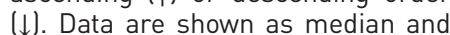
individual results. The time periods ex vivo for the corresponding subgroups were significantly shorter for $25^{\circ} \mathrm{C}$ in ascending order (MannWhitney test $p<0.0001$ ), but for $32^{\circ} \mathrm{C}$ and for $37^{\circ} \mathrm{C}$ they were significantly shorter in descending order (MannWhitney test for $32^{\circ} \mathrm{C}: \mathrm{p}<0.0001$; for $37^{\circ} \mathrm{C}$ : $\mathrm{p}<0.00011$.

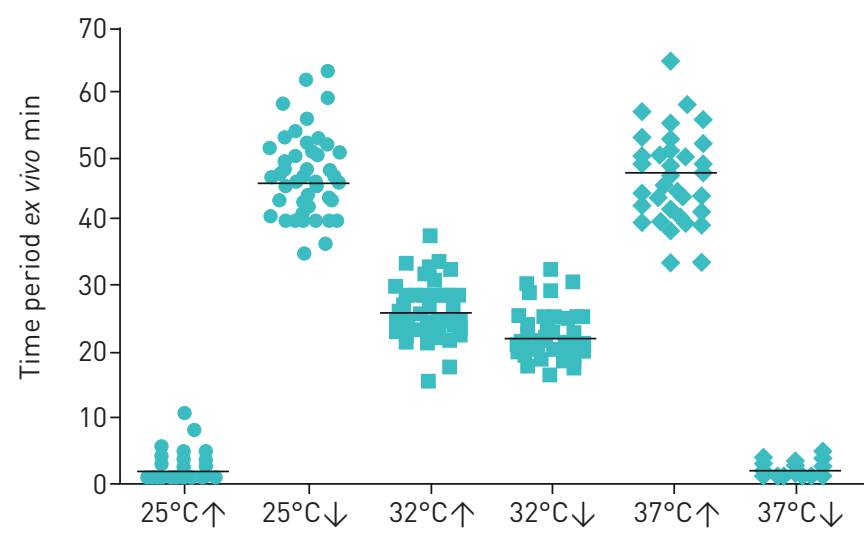



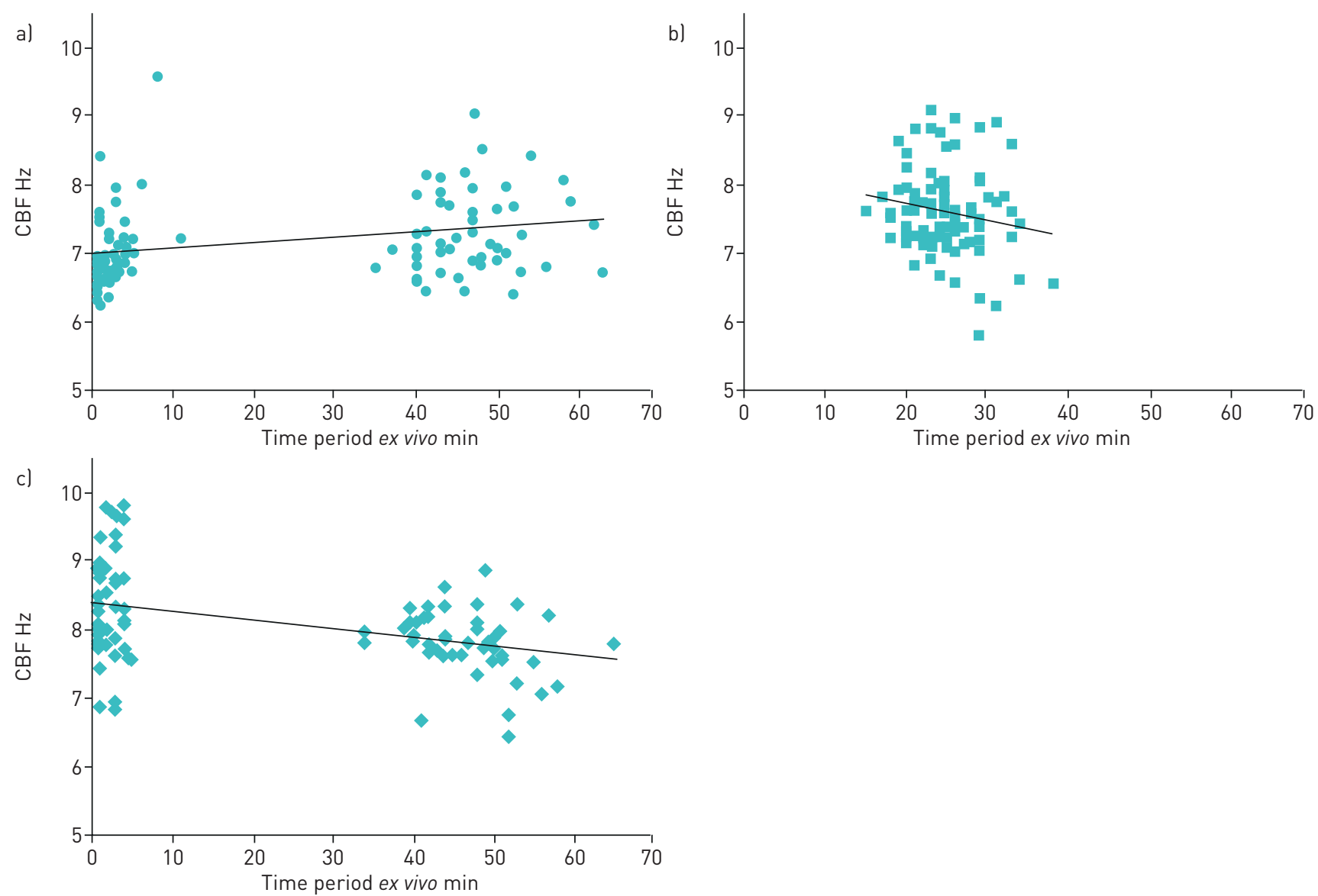

FIGURE 4 Association between the time periods ex vivo and the ciliary beat frequency (CBF) measured at a) $25^{\circ} \mathrm{C}$, b) $32^{\circ} \mathrm{C}$ and $\left.\mathrm{C}\right) 37^{\circ} \mathrm{C}$. Data are shown as individual results and linear regression lines. There was a significant correlation for $25^{\circ} \mathrm{C}$ ( $p=0.0002$, Spearman $r=0.368$, slope of the regression line +0.008$)$ and for $37^{\circ} \mathrm{C}(p<0.0001$, Spearman's rank $r=-0.391$, slope of the regression line -0.012$)$, but not for $32^{\circ} \mathrm{C}(p=0.162$, Spearman's rank $r=-0.141$, slope of the regression line -0.024 ).

\section{Discussion}

The CBF in healthy individuals is dependent on several parameters such as $\mathrm{pH}$, surrounding temperature and possibly age. In neonatal respiratory cilia the mean CBF measured at body temperature was $14 \mathrm{~Hz}$ and decreased by $9.1 \%$ on cooling to $32^{\circ} \mathrm{C}$, respectively increased by $8.5 \%$ on warming to $40^{\circ} \mathrm{C}$ [26]. In an early study a linear increase in $\mathrm{CBF}$ between $19^{\circ} \mathrm{C}$ and $32^{\circ} \mathrm{C}$ and a plateau between $32^{\circ} \mathrm{C}$ and $40^{\circ} \mathrm{C}$ has been described [27]. In another study no significant difference in $\mathrm{CBF}$ was observed between nasal and tracheal cilia when comparing extreme temperatures from $5^{\circ} \mathrm{C}$ to $50^{\circ} \mathrm{C}[28]$.

Pulmonary centres usually measure ciliary function at $37^{\circ} \mathrm{C}[16-19]$ or at $25^{\circ} \mathrm{C}[4,20-22]$, while the physiological nasal mucosal temperature on the nasal mucosa is $\sim 30^{\circ} \mathrm{C}$ to $34^{\circ} \mathrm{C}$ [15]. In our study we compared the $\mathrm{CBF}$ at the three temperatures $25^{\circ} \mathrm{C}, 32^{\circ} \mathrm{C}$ and $37^{\circ} \mathrm{C}$ and established normative values for these temperatures. We were able to show a highly significant difference among the groups: the median CBF was $7.0 \mathrm{~Hz}$ at $25^{\circ} \mathrm{C}, 7.6 \mathrm{~Hz}$ at $32^{\circ} \mathrm{C}$ and $8.0 \mathrm{~Hz}$ at $37^{\circ} \mathrm{C}$. Such difference might have been expected but has never been proven before. Due to a sufficient number of healthy participants, we were able to calculate 95\% confidence intervals for the three temperatures. Previously published data showed higher CBF of $\sim 13 \mathrm{~Hz}$ (range $11.5-14.6 \mathrm{~Hz}$ ) at $37^{\circ} \mathrm{C}[18,29]$ suggesting that $\mathrm{CBF}$ is not only affected by temperature. Other factors such as $\mathrm{pH}$ of the media, storage time and conditions, observer and the technique used to measure CBF might be involved. Even if normative ranges may still need to be centre dependent in the near future, our data not only establish normative values in our own institution but can also contribute to establish a consensus among different centres, because the influence of temperature on CBF was clearly shown in a setting in which other factors were kept constant. In such context, it might also be useful to investigate the influence of other potential factors such as $\mathrm{pH}$ that were not measured in this study.

It has been shown that the ex vivo lifetime of nasal ciliary cells is limited and that these cells have to be transferred to a culture medium for analysis immediately [30]. Under optimal conditions the CBF can 

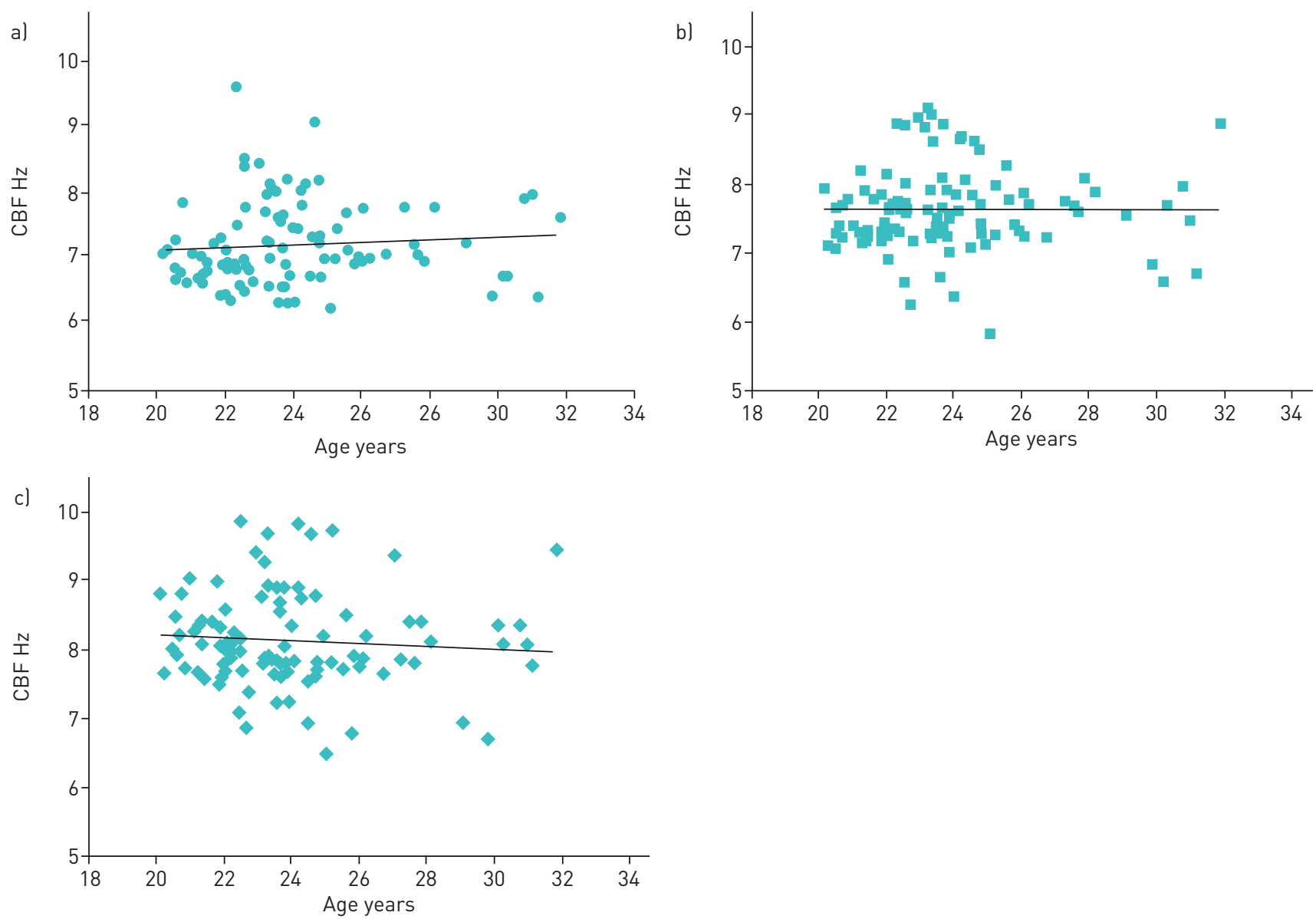

FIGURE 5 No significant correlation between age of the participants and ciliary beat frequency (CBF) measured at a) $25^{\circ} \mathrm{C}$, b) $32^{\circ} \mathrm{C}$ and $\left.\mathrm{C}\right) 37^{\circ} \mathrm{C}$ : $25^{\circ} \mathrm{C}, p=0.051$, Spearman's rank $r=0.196$, slope of the regression line $+0.022 ; 32^{\circ} \mathrm{C}, p=0.521$, Spearman's rank $r=0.065$, slope of the regression line $0.000 ; 37^{\circ} \mathrm{C}, \mathrm{p}=0.336$, Spearman's rank $r=-0.097$, slope of the regression line -0.019 .

even increase initially during the first $3 \mathrm{~h}$, followed by a plateau for up to $9 \mathrm{~h}$ and reduces thereafter. Therefore, measurements of CBF can be performed most reliably for up to $9 \mathrm{~h}$ ex vivo [30]. In our study the maximum time period from nasal brushing to measurement of the CBF was 65 min. The mean time period for the cilia to be ex vivo ranged from 23.6 to $25.5 \mathrm{~min}$ for the measurements at $25^{\circ} \mathrm{C}, 32^{\circ} \mathrm{C}$ and $37^{\circ} \mathrm{C}$ and was not significantly different among the three groups. However, due to the randomisation measuring in ascending or descending order, the time period ex vivo was significantly different between the corresponding subgroups. This could be expected for the corresponding subgroups at $25^{\circ} \mathrm{C}$ and $37^{\circ} \mathrm{C}$ when the measurement was started immediately after nasal brushing or was postponed to the end.

FIGURE 6 Nasal mucosal temperatures are shown as median and individual results. The temperature was significantly higher on the right mucosa compared to the left mucosa (Wilcoxon test, $\mathrm{p}=0.046$ ).

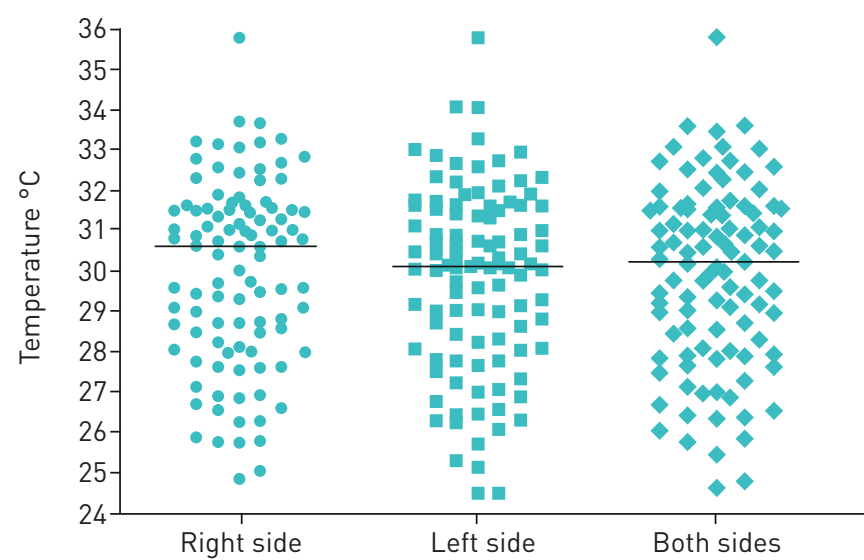


However, for $32^{\circ} \mathrm{C}$ the median time interval ex vivo was only $22 \mathrm{~min}$ and significantly shorter in descending order compared to $26 \mathrm{~min}$ in ascending order. This might be explained by the fact that the heating plate had to be cooled down only by $5^{\circ} \mathrm{C}$ when the measurement was made in descending order and had to be heated up by $7^{\circ} \mathrm{C}$ in ascending order.

We also investigated the association between $\mathrm{CBF}$ and the time period ex vivo. For that measurements at $37^{\circ} \mathrm{C}$ and $32^{\circ} \mathrm{C} \mathrm{CBF}$ decreased over time but surprisingly $\mathrm{CBF}$ increased over time at $25^{\circ} \mathrm{C}$. This observation cannot be explained by the time period ex vivo. $\mathrm{CBF}$ was always significantly higher when the cilia were kept at a higher temperature before the measurements were made. This might indicate that CBF can be obtained ex vivo for a certain time period if cilia are kept at the required temperature but that CBF cannot recover anymore to previous levels if the cilia slowed down ex vivo due to a lower storage temperature. Such a theory would also explain the predisposition to common colds in the winter season.

In our study we found no correlation between the CBF and the age of the participants. This is in accordance with a study investigating 203 individuals between the ages of 3 months and 74 years [31]. In contrast a higher $\mathrm{CBF}$ of $13.6 \mathrm{~Hz}$ was reported in adolescents aged 10 to 19 years compared with $12.2 \mathrm{~Hz}$ in adults older than this [32]. Similar results were obtained in another study in 76 children and adult volunteers aged 6 months to 43 years. The mean CBF was $12.8 \mathrm{~Hz}$ for the paediatric population and significantly higher than $11.5 \mathrm{~Hz}$ for the adult group [19]. From these results the authors even established normal age-related reference ranges. However, the correlation was only weak $(\mathrm{r}=-0.30, \mathrm{p}=0.008)$. Due to the restrictions given by the ethics committee, we were only able to investigate young adults aged 21 to 32 years. As there are contradicting results published in the literature, it would be of clinical and scientific interest to investigate children in our hospital in the future too.

It was our intention to measure the nasal mucosal temperature with a simple noninvasive method, and therefore we chose a contactless infrared thermometer. Using this device, it was hardly possible to standardise the exact site of measurement on the mucosa. The participants had to keep still for a short time period and hold their breath. The mean mucosal temperature in our patients was $30.2^{\circ} \mathrm{C}$ and the range was 24.7 to $35.8^{\circ} \mathrm{C}$. We found a significant difference between each side of the mucosa: the median temperature was $0.5^{\circ} \mathrm{C}$ higher at the right nasal mucosa. Differences of $2.0^{\circ} \mathrm{C}$ between inspiration and expiration have already been shown [33]. In a recent publication the nasal mucosal temperature was measured in a total of 44 nasal cavities with a sophisticated method [34]. The authors inserted a thermocouple into the nasal cavity under direct visualisation and measured the temperature during inspiration and expiration at two sites, site 1 the nasal vestibule and site 2 across the head of the inferior turbinate. During inspiration the mucosal temperature was $29.6^{\circ} \mathrm{C}$ at site 1 , which was not significantly different from $30.0^{\circ} \mathrm{C}$ at site 2. During expiration the mucosal temperature was $33.7^{\circ} \mathrm{C}$ at site 1 and significantly lower than $34.1^{\circ} \mathrm{C}$ at site 2 [34]. Although our participants usually held their breath in the middle of a breathing cycle, the results are well in accordance with these data and can best be compared with the mucosal temperature at site 1 . In our study we analysed healthy individuals and found no abnormal CBP at the different temperatures. It has been suggested that CBP in PCD with extremely stiff beating and recovery strokes (CCDC39/40 mutations) or reduced proximal bending (DNAH11 mutation) can better be evaluated at $25^{\circ} \mathrm{C}$ [4], but analysis of $\mathrm{CBF}$ below $37^{\circ} \mathrm{C}$ might also risk $\mathrm{PCD}$ misdiagnosis [35]. In this study $\mathrm{CBF}$ and $\mathrm{CBP}$ were measured in healthy individuals, while changes in the surrounding conditions such as temperature, $\mathrm{pH}$ or time ex vivo might have more effect on mutated cilia, such as different PCD variants. Our own data and the published data from the literature indicate that the physiological temperature on the nasal mucosa is $\sim 30-34^{\circ} \mathrm{C}$. According to these results, the most appropriate temperature at which to measure the $\mathrm{CBF}$ is $32^{\circ} \mathrm{C}$ and not $25^{\circ} \mathrm{C}$ or $37^{\circ} \mathrm{C}$ as previously suggested.

Conflict of interest: None declared.

\section{References}

1 Knowles MR, Daniels LA, Davis SD, et al. Primary ciliary dyskinesia. Recent advances in diagnostics, genetics, and characterization of clinical disease. Am J Respir Crit Care Med 2013; 188: 913-922.

2 Kartagener M. Zur Pathogenese der Bronchiektasen. Bronchiektasien bei Situs viscerum inversus. Beitr Klein Tuberk 1933; 83: 489-501.

3 Baz-Redón N, Rovira-Amigo S, Paramonov I, et al. Implementation of a gene panel for genetic diagnosis of primary ciliary dyskinesia. Arch Bronconeumol 2020; in press [https://doi.org/10.1016/j.arbres.2020.02.010].

4 Raidt J, Wallmeier J, Hjeij R, et al. Ciliary beat pattern and frequency in genetic variants of primary ciliary dyskinesia. Eur Respir J 2014; 44: 1579-1588.

5 Davis SD, Ferkol TW, Rosenfeld M, et al. Clinical features of childhood primary ciliary dyskinesia by genotype and ultrastructural phenotype. Am J Respir Crit Care Med 2015; 191: 316-324.

6 Goutaki M, Maurer E, Halbeisen FS. The International Primary Ciliary Dyskinesia Cohort (iPCD Cohort) methods and first results. Eur Respir J 2017; 49: 1601181. 
7 Kuehni CE, Frischer T, Strippoli MP, et al. Factors influencing age at diagnosis of primary ciliary dyskinesia in European children. Eur Respir J 2010; 36: 1248-1258.

8 Davis SD, Rosenfeld M, Lee HS, et al. Primary ciliary dyskinesia: longitudinal study of lung disease by ultrastructure defect and genotype. Am J Respir Crit Care Med 2019; 199: 190-198.

9 Marthin JK, Petersen N, Skovgaard LT, et al. Lung function in patients with primary ciliary dyskinesia: a cross-sectional and 3-decade longitudinal study. Am J Respir Crit Care Med 2010; 181: 1262-1268.

10 Shah A, Shoemark A, MacNeill SJ, et al. A longitudinal study characterising a large adult primary ciliary dyskinesia population. Eur Respir J 2016; 48: 441-450.

11 Barbato A, Frischer T, Kuehni CE, et al. Primary ciliary dyskinesia: a consensus statement on diagnostic and treatment approaches in children. Eur Respir J 2009; 34: 1264-1276.

12 Lucas JS, Barbato A, Collins SA, et al. European Respiratory Society guidelines for the diagnosis of primary ciliary dyskinesia. Eur Respir J 2017; 49: 1601090.

13 Collins SA, Walker WT, Lucas JS. Genetic testing in the diagnosis of primary ciliary dyskinesia: state-of-the-art and future perspectives. J Clin Med 2014; 3: 491-503.

14 Rubbo B, Shoemark A, Jackson CL, et al. Accuracy of high-speed video analysis to diagnose primary ciliary dyskinesia. Chest 2019; 155: 1008-1017.

15 Lindemann J, Leiacker R, Rettinger G, et al. Nasal mucosal temperature during respiration. Clin Otolaryngol Allied Sci 2002; 27: 135-139.

16 Jackson CL, Behan L, Collins SA, et al. Accuracy of diagnostic testing in primary ciliary dyskinesia. Eur Respir J 2016; 47: 837-848.

17 Hirst RA, Jackson CL, Coles JL, et al. Culture of primary ciliary dyskinesia epithelial cells at air-liquid interface can alter ciliary phenotype but remains a robust and informative diagnostic aid. PLoS One 2014; 9: e89675.

18 Papon JF, Bassinet L, Cariou-Patron G, et al. Quantitative analysis of ciliary beating in primary ciliary dyskinesia: a pilot study. Orphanet J Rare Dis 2012; 7: 78.

19 Chilvers MA, Rutman A, O'Callaghan C. Functional analysis of cilia and ciliated epithelial ultrastructure in healthy children and young adults. Thorax 2003; 58: 333-338.

20 Chapelin C, Coste A, Reinert P, et al. Incidence of primary ciliary dyskinesia in children with recurrent respiratory diseases. Ann Otol Rhinol Laryngol 1997; 106: 854-858.

21 Jorissen M, Willems T, Van Der Schueren B, et al. Ultrastructural expression of primary ciliary dyskinesia after ciliogenesis in culture. Acta Otorhinolaryngol Belg 2000; 54: 343-356.

22 Knowles MR, Ostrowski LE, Leigh MW, et al. Mutations in RSPH1 cause primary ciliary dyskinesia with a unique clinical and ciliary phenotype. Am J Respir Crit Care Med 2014; 189: 707-717.

23 Thomas B, Rutman A, O'Callaghan C. Disrupted ciliated epithelium shows slower ciliary beat frequency and increased dyskinesia. Eur Respir J 2009; 34: 401-404.

24 Sisson JH, Stoner JA, Ammons BA, et al. All-digital image capture and whole-field analysis of ciliary beat frequency. J Microsc 2003; 211: 103-111.

25 Hyndman RJ, Yanan Fan Y. Sample quantiles in statistical packages. Am Stat 1996; 50: 365-361.

26 O'Callaghan C, Achaval M, Forsythe I, et al. Brain and respiratory cilia: the effect of temperature. Biol Neonate 1995; 68: 394-397.

27 Green A, Smallman LA, Logan ACM, et al. The effect of temperature on nasal ciliary beat frequency. Clin Otolaryngol Allied Sci 1995; 20: 178-180.

28 Clary-Meinesz CF, Cosson J, Huitorel P, et al. Temperature effect on the ciliary beat frequency of human nasal and tracheal ciliated cells. Biol Cell 1992; 76: 335-338.

29 Chilvers MA, O'Callaghan C. Analysis of ciliary beat pattern and beat frequency using digital high speed imaging: comparison with the photomultiplier and photodiode methods. Thorax 2000; 55: 314-317.

30 Sommer JU, Gross S, Hörmann K, et al. Time-dependent changes in nasal ciliary beat frequency. Eur Arch Otorhinolarygol 2010; 267: 1383-1387.

31 Jorissen M, Willems T, Van der Schueren B. Nasal ciliary beat frequency is age independent. Laryngoscope 1998, 108: 1042-1047.

32 Roth $\mathrm{Y}$, Aharonson EF, Teichtahl H, et al. Human in vitro nasal and tracheal ciliary beat frequencies: comparison of sampling sites, combined effect of medication, and demographic relationships. Ann Otol Rhinol Laryngol 1991, 100: 378-384.

33 Lindemann J, Keck T, Scheidhauer MO, et al. Nasal mucosal temperature in relation to nasal airflow as measured by rhinomanometry. Am J Rhinol 2007; 21: 46-49.

34 Bailey RS, Casey KP, Pawar SS, et al. Correlation of nasal mucosal temperature with subjective nasal patency in healthy individuals. JAMA Facial Plast Surg 2017; 19: 46-52.

35 Jackson CL, Goggin PM, Lucas JS. Ciliary beat pattern analysis below $37^{\circ} \mathrm{C}$ may increase risk of primary ciliary dyskinesia misdiagnosis. Chest 2012; 142: 543-544. 